\title{
LAS CECAS CATALANAS Y LA ORGANIZACIÓN TERRITORIAL ROMANO-REPUBLICANA
}

\author{
POR \\ ARTURO PÉREZ ALMOGUERA \\ Universitat de Lleida
}

\section{RESUMEN}

La numismática puede proporcionar indicios importantes para la reconstrucción de las primeras organizaciones territoriales romanas en Hispania. En el nordeste, la uniformidad de sus emisiones republicanas frente a la heterogeneidad de las del mediodía, sugiere unos proyectos organizativos para un amplio territorio, uno a fines del s. II e inicios del I, certificado por la arqueología y ortodoxamente romano, y otro anterior, a inicios del s. II, que se basó en las realidades indígenas. Ante el silencio de las fuentes escritas, el análisis global de cada ceca y sus problemas de ubicación son elementos a considerar en el intento de reconstrucción de ambos.

\section{SUMMARY}

Numismatics can represent an important trace when trying to reconstruct the first Roman territorial organizations in Hispania. The uniformity of the Republican issues in the North-Est -in contrast to the heterogeneity of those in the South - suggests unified organizational projects for a wide territory: one at the end of the 2 nd century and the start of the 1st, truly Roman and certified by the Archaeology; a previous one at the start of 2 nd century was based on indigenous realities. Due to the silence of the written sources, this reconstruction work should take into account both the global analysis of each mint as well as their uncertain location.

\section{INTRODUCCIÓN}

Una vez comprobada por la investigación en las dos últimas décadas la fundación de entidades urbanas ortodoxamente romanas en todo el nordeste hispano y la correspondiente planificación de sus territoria a fines del siglo il a. C. $-\mathrm{O}$ inicios del siguiente-, se planteó lógicamente el problema del status ciudadano para unas realidades que mostraba la arqueología y de las que nada nos decían las fuentes escritas ni la escasa epigrafía del momento. Se apuntó entonces que «tan sólo la numismática nos proporciona algunos datos no siempre seguros ni fáciles de interpretar en un contexto histórico» (Pena, 1984, 49). Por ese terreno se encamina nuestro trabajo. Éste se centra en la actual Cataluña, afectada en su totalidad por el fenómeno que por otra parte, rebasó su marco; ciertamente las cecas más al sur o al oeste merecen otro estudio, que por su singularidad y por razones de extensión no vamos a realizar nosotros.

Fue precisamente al proponerse la posibilidad de una colonia latina en Ampurias cuando se recalcó, como un elemento en contra de tal suposición, el hecho de que un acontecimiento tan trascendental no hubiera tenido eco en la numismática: en buena lógica serían de esperar las monedas fundacionales (Pena, 1988, 29). Se convino en que no las había, lo cual es cierto, pues ninguna con caracteres latinos se acuña por entonces, pero creemos que cabe la posibilidad de que las monedas llamadas ibéricas - no olvidemos que en gran parte son coetáneas de este acontecimiento- nos pueden informar sobre esta organización territorial, siempre partiendo del presupuesto de que nos encontramos ante unas fundaciones de «condición jurídica híbrida», como hace muchos años denominó E. Gabba a los casos problemáticos que mencionaban en Hispania las fuentes escritas (Carteia, Norba, Pompaelo, Graccurris...) (Gabba, 1973, 296). Probablemente se trataba de fundaciones en lo formal ortodoxamente romanas pero que eran como mucho oppida ciuium Romanorum como menciona en el siglo I d. C. Plinio, o ciudades mixtas en las que privaba el elemento ibérico como demuestra la epigrafía (de hecho los documentos latinos, como es bien sabido, no empiezan a proliferar sino con Augusto, alcanzando su mayor densidad a fines del s. I y durante el il d. C.). Pero también, en la misma línea, las monedas anteriores en cien años que aparecen, salvo algunas excepciones, tras la pacificación de Catón con leyenda ibérica y módulos romanos, nos pueden dar las líneas esenciales de una primera ordenación del nordeste peninsular - ésta no «a la romana» sino sobre realidades indígenas - que se produce precisamente en el momento en que se procede a la primera división provincial, claro exponente del deseo de permanencia de los vencedores de la segunda guerra púnica, que les había traído a la Península y durante la que se habrían emitido las dracmas de imitación ampuritana con leyenda ibérica, a las que también atenderemos como exponente de una realidad 
con que se hallaron los romanos en sus primeros años de presencia. Nuestro propósito principal es, mediante el análisis de los problemas que cada una de las cecas plantea, ver la posible relación de sus emisiones con la organización territorial correspondiente a los dos momentos clave: inicios del siglo II a. C. y fines del mismo e inicios del I a. C.

$\mathrm{Al}$ enfrentarnos a ello hay que resaltar la falta de hallazgos numismáticos en contextos estratigráficos homogéneos, lo que conlleva aún controversias cronológicas que pueden verse todavía sujetas a variaciones en función de futuros hallazgos en estratigrafía. No obstante, es cierto que el amplio marco cronológico en que hoy se integran las distintas series es aceptable en líneas generales a pesar de su poca precisión -o quizás por ello-, constituyendo un elemento indicativo que utilizaremos en nuestro trabajo. En todo caso, desde presupuestos extra-numismáticos, tendremos en cuenta los referentes históricos que puedan tener algo que ver con las pretendidas cronologías. En general se acepta, creo que acertadamente, que las monedas ibéricas cumplen esencialmente una función militar, de pago a las exigencias de los romanos, y no son un elemento comercial que circule sino subsidiariamente y en poca cantidad, aunque es cierto que en algún caso ello no resulta claro; no obstante si bien es cierto que ninguna de las cecas que tratamos cuenta con argumentos como para dudarlo, sí ocurre, por ejemplo, con otro taller significativo que escapa a los límites geográficos que nos hemos impuesto, el de Arse-Sagunto, cuyas acuñaciones es posible que sean resultado más de la madurez política y económica que de una imposición militar (Aranegui, 1994, 36; en contra García-Bellido, 1990, 68-71: al menos la plata nace con la segunda guerra púnica y finaliza hacia 170).

Recordemos una vez más que las localidades que vamos a tratar ejercerán una suerte de capitalidad, que se eleva a la categoría de regional si las emisiones son en plata, a partir de las primeras emisiones con metrología romana, lo que debía responder a una realidad con que se encontraron los conquistadores. Hay sin embargo para los primeros tiempos un problema no resuelto: el de las dracmas de imitación ampuritana que presentan leyendas al parecer carentes de sentido - desde ilegibles a incorrectas pasando por anepígrafas e incluso con la imitación del propio nombre de Emporion- (Villaronga, 1979, 113; id., 1994, 33); de ellas sólo tomaremos las que nos dan nombres seguros, y éstas se reducen a baŕkeno, iltiŕta, iltiŕka y taŕakon. De las posibles de kese ya trataremos en su apartado correspondiente. Quizás también pudiera tomarse en considera- ción las que presentan la leyenda olosortin, que nos recuerda a los olossitani mencionados en un documento epigráfico emporitano y la actual población de Olot, sin que podamos ir más allá de recalcar el parecido toponímico (Untermann, 1975, 179).

\section{LAS CECAS IBÉRICAS REPUBLICANAS}

Se trate de imitaciones emporitanas o de denarios ibéricos y bronces, vamos a sintetizar lo que sabemos. Abordaremos las cecas por orden alfabético, transcripción de la escritura ibérica usada siempre en sus leyendas monetales. Prescindimos por tanto de las dracmas de Emporion y Rhode, localidades ortodoxamente griegas.

abariltur emite en la segunda mitad del siglo II a. C. Produce raras piezas en bronce - «moneda anormal» según Gómez Moreno (Siles, 1985)—, con reverso perro o toro. Es de discutida ubicación, a lo que no son ajenas precisamente sus características tipológicas que la alejan de los grupos conocidos. Aunque Villaronga las incluya entre las cecas ibéricas catalanas (Villaronga, 1982; id., 1994, 203 : en concreto entre las layetanas), no es opinión unánime, aunque sí hay una tendencia a creerlo en virtud del lugar de hallazgo de las piezas. Las estudió M. Campo, quien pensó en una posible influencia cesetana, lo que sería un indicio para su ubicación, considerando que, además, a esta ceca debían adscribirse buen número de monedas anepígrafas, cuyo lugar de emisión se ignoraba, por sus representaciones en anverso y reverso, lo que también aceptó Villaronga (Campo, 1974, 226; Villaronga, 1979, 212). Por su parte, Guadán las creyó relacionables con el grupo ausetano (Guadán, 1969, 197). Untermann, admitiendo su situación costera o cercana a la costa, indica tal posibilidad en el amplio arco que limitan Sagunto al sur y la costa septentrional catalana al norte (Untermann, 1975, 218). Cabría, pues, la posibilidad, admitida por los menos, de que no fuera catalana: se ha creído incluso en un lugar del interior limítrofe entre Valencia y Castilla (Martín Valls, 1967, 20).

aŕketuŕki es una ceca con abundantes bronces de sus tres emisiones fechadas tanto en la primera como la segunda mitad del siglo II a.C. - no es seguro que llegaran al siguiente-, también de ubicación discutida: aunque Villaronga la supuso cercana al Ebro por la abundancia de ejemplares en el hallazgo de Azaila (Teruel) (Villaronga, 1979, 191; id., 1982, 160 ; id., 1994, 182), y también otros autores se de- 
cantaron por una situación meridional - siempre dentro de los límites de Cataluña o la zona inmediata aragonesa- (Mateu Llopis, 1947, 56; Beltrán, 1953, 29), la tendencia ha sido ubicarla Segre arriba (Untermann, 1975, 19), y concretamente en la pirenaica La Seo de Urgel (Martín Valls, 1967, 221), en el más apto valle de la zona y en camino hacia la Cerdaña. - uŕki habría dado origen a Urgel. Esa es nuestra opinión (Pérez Almoguera, 1995; id., e.p. a): en concreto la cabecera de esta ciuitas debía encontrarse en Castellciutat, germen de La Seo, donde se han documentado restos cerámicos correspondientes al siglo II a.C. (Padró, 1988), indicio de que en efecto hubo hábitat; es cierto que el dato no es suficiente para suponer que éste fuese importante, pero no olvidemos que esta zona careció de poblaciones de entidad incluso en época altoimperial, como parece desprenderse de lo conocido en torno a la cercana Iulia Liuica (Lívia) donde priva la población dispersa. Su situación en zona limítrofe explicaría, además, por qué la primera de sus emisiones se inscribe dentro del grupo de influencia ausetana y las otras dos en el iltirtense. Es interesante que señalemos el intento de englobar, tras la pacificación de Catón en el 195, los Pirineos orientales en la red urbana y en la organización del territorio, que, sobre bases indígenas, se llevó a cabo entonces (ore, como veremos, podría ser un caso similar), lo que no parece haber tenido continuidad cuando se produce una nueva organización ya «a la romana» a fines de siglo o inicios del siguiente: las fundaciones que conocemos lo serán más al sur, en el pre-Pirineo como mínimo (Aeso, Labitolosa), alcanzando el rango municipal en el alto imperio. No obstante, es muy posible que, a pesar de ello, aunque sin status, aŕketuŕki continuara con vida: se trataría de la Orgia que cita Ptolomeo como ilergete (II, 6, 69), y ya en el bajo imperio alcanzaría notoriedad siendo la Vrgellum que aparece a fines del mismo como obispado (al menos desde 527). Es posible que, dada la etapa de inseguridad del momento, el carácter de marginalidad y plaza fuerte significara su nueva potenciación: las ciudades pre-pirenaicas, si no desaparecen totalmente, no consta que fueran obispados. En cualquier caso la localidad se encontraba en zona fronteriza, lo que a su vez reforzaría su valor: ya hemos visto como Ptolomeo la situaba entre las ciudades ilergetas, pero antes pudo ser ceretana, según se deduce de las noticias de Estrabón (III, 4, 41) y Plinio (III, 22, 23), en el límite con los lacetanos.

auśesken se venía considerando como un etnónimo que hacía referencia al populus de los ausetani, ampliamente mencionado por las fuentes escritas alusivas a la segunda guerra púnica (Livio 21, 23, 2; $21,61,8 ; 29,2,5 ; 29,3,3$ ) como aliado de los ilergetes, siendo tras éste el más importante del interior catalán (conoce también la institución de los régulos). Es también citado en acontecimientos posteriores $(34,20,1 ; 39,56,1)$. Sin embargo, Untermann considera que este etnónimo, como los otros terminados en - sken, se refiere a los habitantes de una ciudad determinada (Untermann, 1992, 25), en este caso Auso o Ausa como aparece citada por Ptolomeo (II, 6, 6), que, como su nombre indica, era la localidad principal de los ausetanos desde el momento que presenta un nombre derivado del mismo. A ésta debe referirse la cita de César (b.c. 1, 60,2). Será municipio de ciudadanos latinos (Plinio, N.H. III, 23) en el alto imperio (IRB 86) y corresponde a la actual Vic. $\mathrm{Su}$ papel proponderante en los primeros tiempos de presencia romana se acrecienta cuando observamos su amonedación de denarios y divisores a inicios del siglo II a. C. Aun cuando emite menos plata que kese o iltiŕta, las únicas otras dos cecas indígenas que lo hacen por entonces, ello puede ser indicio de capitalidad regional. Es posible que esta emisión sea coetánea de los primeros bronces (Villaronga, 1979, 76, 129, 138, 208; id., 1982, 163; id., 1994, 185), pero así como la plata cesa, los bronces llegan hasta finales de siglo y señalan el fin de las emisiones locales, indicio quizás de que no se produjo allí una fundación romana contemporánea de otras bien documentadas, pero ello no parece avenirse bien con el destacado papel regional que antes había jugado y que por otros motivos sospechamos que continuó teniendo, lo que supondría un engarce con el posterior municipio. Las distancias que indican unos miliarios fechados a fines de siglo II a. C. (IRC I 175, 176, 181) cuadran bien con la ubicación de Vic, que sigue haciendo sospechar su preeminencia en la zona, y el llamado monumento de Malla, también cercano a la capital ausetana y fechado por los mismos años (Rodà, 1992, 18), podía formar parte de la ordenación del territorio que se lleva a cabo a fines del siglo II o inicios del I a.C., lo que nos mueve a admitir que el territorio de Auso fue por entonces reorganizado y debió conllevar un nuevo establecimiento urbano. El que arqueológicamente no se haya documentado no es obstáculo insalvable para admitirlo: ni siquiera en el alto imperio contó con un núcleo urbano de entidad, aunque la llanura en torno a Vic aparece ocupada, al menos, desde el siglo ir a. C. (Molas, 1982, 122). Por otro lado tampoco cuenta prácticamente con epigrafía, aun siendo municipio.

baitolo es el antecedente del municipio de Baetulo (Badalona) y emite bronces en la primera mi- 
tad del siglo I a. C. (Villaronga, 1979, 224; id., 1994, 198), aunque es posible que comience algo antes, en el siglo II (Villaronga, 1982, 177). Dado que se trata de una población layetana, es tentador poner en relación el inicio de sus emisiones con el fin de las de laiesken, como explicamos en su apartado correspondiente, y ello en función de su cercanía a Barcelona, probablemente la sede de este otro taller. En cualquier caso, la aparición de las monedas baetulonenses puede relacionarse con la fundación de la ciudad en torno al 100 a. C., fecha comprobada en el estudio del poblamiento rural por $\mathrm{M}$. Prevosti (Prevosti, 1981) y por los datos que se deducen del recinto amurallado (Guitart, 1993 b, 57), aunque hay partidarios de retrasar la fundación hasta aproximadamente el 75 a. C. (Aquilué - Subías, 1986). La nueva fundación no sería, como se ha propuesto, «la que sustituyó a la prerromana que acuña moneda con el nombre de Baitolo» (Pina, 1993, 79), sino que fue ésta la que las acuñó. La localidad será citada posteriormente por Mela (II, 90) y por Plinio (III, 22) como englobada en el conuentus Tarraconensis.

baŕkeno (también baŕkeno) es un topónimo que figura en dracmas de imitación emporitana emitidas durante la segunda guerra púnica (Untermann, 1975, 180; Villaronga, 1979, 113; id., 1994, 49). Su reducción a Barcelona parece evidente. El nombre no vuelve a aparecer en posteriores emisiones y el problema se imbrica de alguna manera con el de la ceca de laieśken, a la que remitimos.

baśti, de la que hay una conocida homónima en la Ulterior (hoy Baza), era conocida por una sola pieza a través de la clásica obra de Vives. Es dudosa y Villaronga no la recoge en su relación de cecas ibéricas catalanas: se conocía sólo un semis y cabía la posibilidad de que se tratara de una lectura incompleta (Martín Valls, 1967, 31). Recientemente, Villaronga da noticia de una dracma de imitación con la misma leyenda (Villaronga, 1994, 53, núm. 112). Es muy probable que haya que ubicarla fuera de Cataluña, aunque sea tentador ponerla en relación con la Bassi que cita Ptolomeo como población de los Castellani (II, 6, 70), para la que no habría más argumento que el parecido toponímico. Se ha propuesto su ubicación en el curso bajo del Ebro y en la zona de Sagunto (Untermann, 1975, 220): Guadán opta decididamente por situarla en este último lugar, en la esfera de las monedas de arse (Guadán, 1969, 178). Lo expresado nos mueve a prescindir de ella en nuestro estudio. biluaon también es conocida por un único ejemplar y asimismo se cree que es catalana, pero no tenemos seguridad de ello. Por lo demás, su cronología es también imprecisa (Villaronga, 1982, 182).

eśo emitió escasamente bronces en la primera mitad del siglo I a.C. (Villaronga, 1982, 162), quizás algo antes (Guadán, 1980, 95). Villaronga la situaba en el grupo sedetano, si bien luego lo hizo en el ilergete (1994, 183); Guadán lo hace en el de iltiŕta $(1969,191)$ con otras acuñaciones ciertamente aragonesas, como también lo hizo Untermann (1964, 145). Ello no es óbice para que el propio Villaronga la identifique con la romana Aeso, la actual Isona, en el pre-Pirineo, como efectivamente suele ser admitido, aunque sin embargo Untermann no cree, por razones lingüísticas, que se trate de ésta (Untermann, 1975, 201). Por nuestra parte, aceptamos la identificación con la localidad aesonense, ciudad estipendiaria que menciona Plinio (N.H. III, 23) formando parte del conuentus Tarraconensis, y que después, desde época flavia, fue municipio. Ptolomeo la cita como localidad lacetana (II, 6, 71). La fecha inicial propuesta para la aparición de sus monedas parece avenirse bien con la de su fundación - contemporánea de otras varias como vemos-, según se desprende de los datos de las intervenciones arqueológicas que se vienen regularmente realizando desde 1987: en concreto la de 1992, junto a la muralla, certificó la fundación de la ciudad a fines del siglo II e inicios del I a.C. (Payà et al., 1994), al parecer sobre un núcleo anterior de importancia desconocida. En cierto sentido puede considerarse sucesora de aŕketuŕki pero sólo en tanto que es la ciudad más norteña del interior que deja de emitir al parecer cuando lo hace eso, que pasa a ser la ceca más septentrional.

euśtibaikula o euśti (sus monedas presentan ambas lecturas) fue una ceca relativamente importante si observamos que emite bronces ya a inicios del siglo II a.C. (con varios divisores) y sigue haciéndolo en la segunda parte del siglo, aunque no llega al posterior (Guadán, 1969, 124-125; Villaronga, $1979,129,210)$. Se suele admitir que se trata de la Baicula que cita Ptolomeo entre las localidades ausetanas (II, 6, 69) y de los baeculonenses que Plinio relaciona como estipendiarios del conuentus Tarraconensis (III, 4, 23). Estas citas no hacen sino abundar en que fue localidad de alguna importancia: incluso se pensó en que sus habitantes fuesen los Becensis que aparecen en el Bronce de Ascoli. Es, por lo demás, un topónimo que también se documenta en el sur: hay otra Baecula en Bailén, Jaén 
(Untermann, 1975, 188). Ignoramos su ubicación, si bien tenemos un importante punto de partida como es su inclusión en el territorio de los ausetanos, uno de los más amplios por cierto del interior catalán. Sin gran fundamento se ha propuesto situarla en Roda, Granollers o Besalú (Tovar, 1989, 446, C-605), pero es cierto que tampoco la dispersión de sus monedas nos aclara el problema, pues éstas suelen aparecer en la zona comprendida entre Vic y el Vallés (Crusafont et al., 1986, 29), pero también llegan hasta el valle medio del Ebro e incluso a la Meseta (Martín Valls, 1967, 46). Un elemento que creo debe ser tenido en cuenta es el hecho de que no emite, como hemos visto, a inicios del siglo I, lo que puede ser un indicio de que no se incluyó en la nueva organización territorial del momento, pero que como en el caso de aŕketuŕki continuó con vida posiblemente englobada en el territorio de otra ciuitas, a juzgar por la mención de Ptolomeo. Este último menciona como localidades ausetanas, además de la que nos ocupa y de Ausa, sólo dos más, Gerounda e Udata Therma, es decir, las latinas Gerunda y Aquae Calidae (Gerona y Caldas de Malavella). Que estas dos últimas lo fueran también no es precisamente aceptado por unanimidad y no pocos consideran que se trata de un error del escritor alejandrino, aunque por nuestra parte, y aún teniendo en cuenta los impedimentos orográficos y la lógica de la cercanía emporitana de la región gerundense, lo creemos posible. Por las monedas sabemos que los ausetanos llegan también hasta el Pirineo, en la cuenca alta del Segre, lo que nos da un amplio territorio donde ubicar euśtibaikula. Destaquemos, si aceptamos que fue en algunos momentos localidad de cierta importancia, que hay casos como el de Caldas de Montbui por ejemplo, donde hubo población romana tanto republicana - por allí discurría una antigua vía- como imperial - aunque no se conoce un núcleo urbano de entidad (Miró et al., 1993, 225)-, que bien pudo ser euśtibaikula (Molas, 1982, 40), máxime cuando su nombre antiguo nos es desconocido al demostrarse que no es Aquae Calidae como se creía (ésta es Caldas de Malavella; Nolla, 1993, 660), y además se encuentra situada en la zona de dispersión de las monedas. Ya Villaronga expresó la posibilidad de que en Caldas de Montbui se ubicara nuestra ceca. Por otro lado su situación cercana a tierras de los layetanos podría explicar que, en sus últimas emisiones, el jabalí característico de los ausetanos es sustituido por el ánfora propia de la Leyetania (Villaronga, 1994, 187). En cualquier caso, no podemos ir más allá de suponerla en el amplio marco ausetano, como apuntábamos. ieśo, al igual que su vecina norteña eso, emite bronces a inicios del siglo I a.C. (quizás algo antes según Guadán, 1980, 120), fecha en la que se funda la ciudad según módulos romanos que la arqueología viene poniendo al descubierto en la actual Guissona (Guitart - Pera, 1993, 161). Fue municipio altoimperial con el nombre de Iesso, y es citada por Plinio (N.H. III, 4, 23) y más tarde por Ptolomeo (Iessós; II, 6, 71) como localidad lacetana, no jacetana como aparece en algunas versiones (Tovar, 1989, C-560, 431). No hay disparidades en cuanto a su ubicación en la citada localidad de la comarca ilerdense de la Segarra, aunque en alguna ocasión se haya negado (Crusafont et al., 1986, 31) en base a la distribución de los hallazgos de ejemplares y a la similitud de sus monedas con las de baitolo o ilturo, por lo que se encontraría en la costa. Villaronga consideraría posible esta última probabilidad, pero la evidencia epigráfica la sitúa claramente en Guissona (Villaronga, 1982, 179; id., 1994, 199), donde en el imperio tenemos documentado epigráficamente el ordo Iessonensis (IRC II 73). Reparemos que el ejemplo es interesante por cuanto nos previene de que no necesariamente la circulación monetal nos indica el lugar o zona de emisión con seguridad. No obstante también se ha documentado algún ejemplar en las comarcas orientales de Lérida (Martín Valls, 1967, 48).

iltiŕkesken es posiblemente la ceca que más problemas plantea, pues en este caso se complica por la unanimidad con que ha sido considerada propia de los ilergetes repitiendo el etnónimo que ya aparece en otra ceca distinta, iltiŕta, que es la «capital» de este pueblo. Priva la opinión de que se trató de la moneda de los ilergetes orientales que se encontrarían en torno a Solsona o en la Segarra, en alguna forma distintos a los que se agrupaban en torno a iltiŕta (Villaronga, 1979, 130, 210), en base a los hallazgos conocidos. Más recientemente, por las mismas razones, se ha considerado ceca layetana (Villaronga, 1994, 200). Nuestra propuesta es muy distinta y la creemos en el bajo Ebro, zona sorprendentemente huérfana de cecas conocidas, habitada por los ilercaones o ilergauones, que jugó también un gran papel en los primeros tiempos de presencia romana y que debió contar con un centro importante en atención a las posibilidades comerciales que el curso del Iberus propiciaba de antiguo, así como a las posibilidades agrícolas que conllevaba. Sus monedas se encuentran a lo largo del curso del Ebro y llegan, sin duda a través de su afluente el Segre, hasta el mediodía galo donde son incluso motivo de imitación. También aparecen en las comarcas orientales iler- 
denses y parte de la occidental barcelonesa del Anoia; hay un número considerable en Els Prats de Rei, sede del municipio imperial de Sigarra, y es interesante señalar que Ptolomeo cita esta localidad como ilercaona (II, 6, 63). Recientemente se han documentado también ejemplares en el meollo de las tierras ausetanas (Molas et al., 1994, 49). Desde un prisma filológico, la reducción del ibérico iltiŕkesken al latino presupone la pérdida de la $t$ (como ilturo $=$ Iluro o iltiŕta $=$ Ilerda) y el cambio de la segunda $i$ en $e$ (iltiŕta $=$ Ilerda), lo que nos remite claramente a los ilercaones o ilergaones. En concreto, aceptando que los étnicos en -sken se refieran a los habitantes de una ciudad (Untermann, 1992, 25), ésta sería una Ilerca o Ilerga, y es tentador ponerla en relación con Tortosa, el municipio de Dertosa, o mejor, la antecesora de la misma - no necesariamente ubicada en el mismo solar- dado que aún no se había formado el delta que preside y no hay niveles claros anteriores a Augusto en el casco urbano tortosino (Genera, 1993; Pena, 1993). En cualquier caso Ilercauonia aparece como uno de los sobrenombres del municipio dertosino. Por otra parte, señalemos que, retomando una vieja postura, también la suponían en esa zona Martín Valls y más recientemente Collantes, Fatás o Panosa (Martín Valls, 1966, 49, 108; Collantes, 1987-1989, 29; Fatás, 1992, 226; Panosa, 1992, 203). Es posible que se trate de la Hibera citada por las fuentes alusivas a la segunda guerra púnica y, quizás menos probable, la Tyriche mencionada por Avieno (O.M., 496-503) (Pena, 1989). Parece pues más oportuno situarla en esta zona que no en la otra vecina de los lacetanos como se ha hecho (Padró - Sanmartí, 1992, 193). Señal de su importancia en los primeros tiempos es la acuñación de dracmas (sólo conocemos una) y divisores con la leyenda iltirkeśalir (aquí parece sin duda referirse a una ciudad), claro antecedente de las de bronce de iltiŕkesken que se acuñarán a partir de la primera mitad del siglo II a. C. (García-Bellido, $1993,114)$. Además no se trata de imitaciones ampuritanas, sino de estáteras tarentinas (Villaronga, 1994, 36; en contra García-Bellido, 1993, 114), lo que cuadra mejor con una ubicación marítima que con las menos cosmopolitas tierras del interior. Sus emisiones en bronce llegan hasta el i a.C. (Villaronga, 1979, 223). Señalemos que durante el imperio perdura el recuerdo de la importancia que los ilercavones habían tenido: junto con la cesetana y la ilergete, es la única región (regio Ilergaonum) que cita Plinio en la actual Cataluña (N.H., III 21); por otro lado muy posiblemente se trataba de un pueblo emparentado con los ilergetes, sus vecinos, como en varias ocasiones ha sido señalado. iltiŕta es una de las cecas más prolíficas como corresponde a la cabecera del principal populus, el de los ilergetes, que habitó las tierras interiores de Cataluña y las vecinas aragonesas. Las fuentes escritas correspondientes a la segunda guerra púnica son suficientemente explícitas en destacar su carácter de pueblo más poderoso. Comienzan las acuñaciones con dracmas de imitación emporitana y divisores de imitación massaliota en cantidad relativamente notable a fines del siglo III a. C. (Untermann, 1975, 177; Marchetti, 1978, 358, 360, 365; Villaronga, 1978, 43; id., 1994, 175; Ripollés, 1982 , 264; Pérez - Soler, 1993, 152), lo que puede ponerse en relación con noticias como las que nos da Livio $(28,25,6$ y 34,11$)$ referida a 206 a. C. en que se reclama al régulo ilergete Mandonio erario para pagar al ejército romano (García-Bellido, 1993, 109). Poco después, ya a inicios del siglo siguiente, acuñará denarios (Guadán - Villaronga, 1968, 59), lo que nos sigue indicando la primacía de la localidad tras la conquista como de hecho seguirá teniendo durante toda la etapa republicana en un amplio territorio del interior. Realizará también diversas emisiones en bronce a lo largo de todo el siglo II y primera parte del i a. C. (Villaronga, 1979, 128, 137, 213,225 ), entre ellas las que muestran la representación del lobo - también lo hace en las de plata-, animal totémico de los ilergetes (Pérez - Soler, 1993). La identificación de iltiŕta con el posterior municipio de Ilerda, hoy Lérida, que acuñará con caracteres latinos en época de Augusto, no ofrece dudas. Aunque durante la segunda guerra púnica Livio se refiere a una desconocida Athanagrum como capital de los ilergetes $(21,61,6)$, lo cierto es que, como hemos visto, las monedas y también las fuentes escritas posteriores sólo se refieren a la nuestra. Aun cuando, sin gran fundamento, se ha propuesto otra ubicación, se admite que el núcleo principal de la ciudad prerromana se desarrolló en la colina de la Seu de Lérida donde, a excepción de un pequeño muro fechado en el siglo II a.C., no quedan restos constructivos - pero sí materiales cerámicos mezclados que se remontan al siglo IV a.C.- consecuencia del carácter de fortaleza que el lugar ha tenido a lo largo de la historia hasta fechas muy recientes y que ha significado rebajes y remodelaciones en muy diversas épocas (Pérez Almoguera, 1993, 256; Junyent, 1994, 86). En el llano, la vecina plaza de Sant Joan, también cercana al puente, aparece ya ocupada en la primera mitad del siglo II a.C. y, algo más tarde, otras zonas del casco antiguo. En lo que hace a la circulación monetaria en Lérida, realizada ciertamente con pocos ejemplares, se constata un predominio de la ceca local y de la 
de iltiŕkesken (Ripollés, 1982, 508-512). La presencia de la última puede deberse, como proponemos en su apartado correspondiente, al contacto con el bajo Ebro a través del río principal y de su afluente el Segre. En general la moneda externa es escasa, quizás como consecuencia de la abundacia de emisiones de la ceca local.

ilturo. Las excavaciones de Burriac, en Cabrera de Mar, han certificado que se trata de la localidad indígena que acuñó numerario abundante en bronce desde la primera mitad del s. II. Continúan las emisiones en la segunda parte del mismo (Villaronga, $1979,129,210$; id., 1994, 191) y en torno al cambio de siglo emite la conocida serie que tiene por símbolo la oreja (Crusafont et al., 1986, 30). Probablemente coincide esta última con el traslado de la población al solar - no traslado total, dado que el poblado de Burriac continúa con vida hasta el 50 a. C.- que hoy ocupa Mataró, donde estuvo la romana Iluro, del que es testimonio el ordenamiento territorial, estudiado por M. Prevosti, y los restos más antiguos en Mataró que se fechan entre 120-100 a. C., posiblemente más cerca de la primera fecha que de la segunda (Clariana, 1994, 9, 17). No obstante, recientemente se ha sostenido que la nueva fundación no tuvo lugar hasta 75-50 a. C. (Cerdà et al., 1993, 87), lo que, comprobado también en Gerun$d a$, ha hecho pensar en una reorganización pompeyana (Olesti, 1993, 245). Se pensó que el paso de los cimbrios pudo ser determinante en el cambio de ubicación, situando el núcleo urbano cabecera de la ciuitas donde era más fácil acceder a las fuentes de aprovisionamiento, es decir, junto a la vía Heraclea. Por nuestra parte, las fechas del poblamiento rural que M. Prevosti fijó y los datos de otras localidades (Aeso por ejemplo) indican en todo caso que el núcleo urbano sería la culminación del proceso que se inicia a fines del siglo II a.C. La identificación de la cecas con esta localidad -o localidades- es unánimente aceptada (Untermann, 1975, 190). Así, la ecuación ilturo $=$ Burriac e Iluro = Mataró, aunque en realidad se trate de la misma entidad al ser una sucesora de la otra, es desde hace tiempo recogida en la bibliografía (Ripollés, 1982, 357-369). De hecho la nueva fundación en sus comienzos fue probablemente la que siguió emitiendo con el nombre de ilturo con caracteres ibéricos a inicios del siglo I a.C. Por tanto, Burriac enlazaría con Mataró cronológicamente; es palpable que la población de $\mathrm{Bu}$ rriac comienza a menguar en torno a los años 100 90 a.C. (Miró et al., 1988, 134). Se trata de la localidad que Ptolomeo sitúa entre las layetanas (II, 6,18 ) y la que antes, como oppidum ciuium Roma- norum, citaba Plinio (III, 22). Es también una de las escasas que menciona Mela (II, 90).

kaio es otra ceca de ubicación desconocida de la que se conocen escasas piezas (por supuesto bronces). Ya hace años A. Beltrán la creyó ciudad-cabecera de los loutiscos, con lo que no se encontraría en Cataluña (Martín Valls, 1967, 37). No obstante la localización en ella es probable, por cuanto la representación del caballo piafando que aparece representado en sus monedas las acerca a las de kese (Villaronga, 1982, 147; id., 1994, 173). Por lo demás, se ignora su cronología.

kese. Se admite que corresponde a Tarraco (aun cuando no hay unanimidad; contra ello Alföldy, 1991, 23-24; García-Bellido, 1993, n. 6), localidad ésta última que por su importancia y función de capitalidad es citada por casi todas las fuentes históricas y geográficas que desde fines del s. III a. C. en adelante se refieren a Hispania. Los cesetanos habitaban la zona tarraconense e inmediaciones. kese es seguramente la Kissa que menciona Polibio en plena segunda guerra púnica (Hist. 3, 76, 3-5), donde tuvo lugar una decisiva batalla, lo que también hará Livio $(21,60)$-Cissis la llama éste. Por lo demás Plinio el Viejo se refiere a Tarraco como situada en la regio Cessetania (N.H. III, IV, 21) y lo mismo, ya en el s. II d. C., Ptolomeo (II, 6,17). Es de señalar que éstos últimos sólo hablan de la región en la que Tarraco ejerce una capitalidad y no ya de la ciudad de kese. Parece admisible suponer que la localidad indígena se fundî́ con la romana Tarraco con la cual había convivido durante los primeros tiempos de presencia romana. El problema es que el topónimo Tarraco también parece indígena (aunque Schulten lo creyó etrusco) y es posible que nos encontremos ante una dualidad de nombres (Tovar, 1989, C-627, 454), siendo el de kese el que indicaría su característica de ciudad principal del populus del que toma el nombre. Tal localidad indígena quizás hemos de identificarla - al menos su centro principal - en la parte baja del actual casco urbano de Tarragona, al sudoeste de donde se alzó el recinto amurallado republicano que aún se conserva (Adserias et al., 1993, 177-227), que en principio limitaba el praesidium y en el que quizás en una ampliación llevada a cabo en el s. II a. C. se incluyera el núcleo indígena. Se trata de un «poblado» del que se ignora su superficie total, pero de magnitud considerable, lo que cuadra con su carácter de capitalidad de un populus, y que aparece ocupado al menos desde el siglo v. Recientemente se ha propuesto de nuevo la identificación de Tarrago- 
na con la Callipolis mencionada por las fuentes también por las mismas latitudes (Icart, 1993). Como fuere, sean o no ciudades diferentes todas ellas, lo que parece claro es que la localidad que llevaba el nombre del populus que aparece en las monedas, si no era la misma, debía estar en la vecindad de la ciudad romana o, en todo caso, ésta última no hay duda de que estaba en el territorio de los cesetanos. Se conocen dracmas con la leyenda taŕakonsalir (Villaronga, 1988), imitación de las ampuritanas, acuñadas entre 218 y principios del siglo II a. C. Se había negado no hace mucho su existencia: Ripollés $(1982,374)$ se refiere a que Guadán consideró que se trataba de una acuñación inexistente y por tanto había que desecharla; Fletcher $(1989,823)$, en base a que sólo se conocía una a través de un dibujo con lectura poco clara. El hallazgo de cinco monedas la pasada década demostró su existencia (Villaronga, 1992 b, 93). Para las mismas ha llegado a proponerse una fecha en torno al 250 a. C. (Alföldy, 1991, 23), lo que parece exagerado siendo más prudente la cronología que propone Villaronga. Cese emitirá denarios a mediados del s. II a. C. En principio las citadas dracmas podrían considerarse las antecedentes de los posteriores denarios y bronces con leyenda kese, pero en contra parece haber dos dracmas en que se lee precisamente también kese, lo que vendría a significar que, si son coetáneas de las de taŕakon, hay serios motivos para pensar que, en efecto, se trata de dos localidades diferentes. Sin embargo las dracmas con leyenda kese no presentan una lectura clara (Villaronga, 1988; id., $1992 \mathrm{~b}$; id., 1994, 52 : «... con pequeñas dudas leemos kese»), por lo que quizás se precise el hallazgo de nuevos ejemplares para corroborar con seguridad que tal es la lectura.

Las primeras emisiones en bronce se llevarían, según Gimeno (Gimeno, 1954, 28-30, cuya opinión, sin citarle, sigue Villaronga, 1979, 119; id., 1983, 101), a una data contemporánea de las monedas hispano-cartaginesas, antes de 214/212 a. C., lo que, de ser cierto, abundaría en la presunción de dos poblaciones diferentes. La fecha puede ser discutible, pero es evidente que el signo ke que presentan las consideradas tres primeras emisiones es arcaico, amén de que su estilo y su técnica también están en la misma línea y, aún más, su sistema metrológico. Tras ellas sigue emitiendo, en abundancia, ya en la primera mitad del s. II sin los caracteres arcaicos (Villaronga, 1979, 123), emisiones a las que seguirán otras en la segunda mitad de siglo y en el siguiente, siendo probablemente la ceca más completa del nordeste. A los efectos que nos interesan, es uno de los talleres que tienen actividad en los dos momentos clave de la ordenación territorial romana, a inicios del s. II y a finales del mismo o inicios del siguiente. No es posible, en el grado de inseguridad en que nos movemos, relacionar una o unas series concretas con el momento (o los momentos) específico. Por lo demás, si se trata de Tarraco, —así lo cree también Untermann y con él otros autores (Untermann, 1964; Ripollés, 1982, 372) aunque hemos visto también disidencias- huelgan más comentarios: es la principal ciudad, capital de la Citerior. Si admitimos pues la identidad de Tarraco y kese, resultaría que nos encontramos ante una ceca de extraordinaria duración: desde aproximadamente la segunda guerra púnica hasta época de Tiberio cuando ya era la colonia Triumphalis Tarraco. Añadamos que no existe moneda de plata a nombre de kose como se pretendía, sino que la lectura correcta es tikose (Villaronga, 1979, 113), con lo que podemos prescindir de ella al no tener relación con nuestra ceca.

laieśken plantea importantes problemas en cuanto a su ubicación. No hay duda de su relación con el populus de los laitani, que tiene su asiento en la costa al norte de los cesetani y al sur de los indiketes y en el Vallés por el interior, y que es mencionado por diversas fuentes: Ptolomeo (II, 6, 18), Plinio (sobre la bondad de sus vinos, XIV, 71) o Marcial (en la misma tónica que Plinio; I, 49, 22). Antes nos hemos referido a las dracmas con leyenda baŕkeno. Ha sido tendencia generalizada el suponer una hipotética Laie en Barcelona, antecesora de la colonia Iulia Augusta Paterna Fauentia Barcino que se funda en época de Augusto. Ha sido así posiblemente por el importante papel jugado por la localidad en etapas posteriores de la historia. En cualquier caso, es de retener el hecho de que baŕkeno ya es un topónimo documentado a fines del siglo III a. C. El que ningún ejemplar de estas dracmas se haya documentado en Barcelona nada significa por cuanto son pocos los conocidos (Campo - Granados, 1978; id., 1979) y tuvieron un fin muy inmediato y seguramente poca circulación. Es tentador ponerla en relación con el poblado ibérico documentado en Montjuic que se supone de extensión comparable al de Burriac que mencionábamos a propósito de ilturo y, posiblemente, muy superior a los otros vecinos (Padró - Sanmartí, 1992, 191), aunque no puede asegurarse por haber desparecido a consecuencia de la explotación de la montaña en diversas épocas; no obstante, unos silos de gran tamaño investigados parecen atestiguar que se trataba de un centro comercial de importancia (materiales de los siglos IV y III a. C.; Blanch et al., 1994) que llega hasta el 
siglo I d. C. (Barberà - Dupré, 1984, 67). Como fuere, el hecho de que no vuelva a emitir no deja de llamar la atención por cuanto hay que suponer que se trataba de una de las ciudades más notables de Cataluña con que se encontraron los romanos a su llegada, prescindiendo por supuesto de un urbanismo desarrollado o no, y las mismas suelen seguir siendo cabeceras de su zona durante el siglo siguiente. Esta sea quizás la razón más importante, a mi entender, para suponer a laie continuadora de baŕkeno. El hecho de la duplicidad de nombres no necesariamente lo contradice: pensemos en el caso taŕakon-kese y en que es presumible que el centro principal de cada pueblo tendiera a tener por ciudad-cabecera una que ostentara el nombre de éste o un derivado. Pudiera pues tratarse de la misma. Hay sin embargo elementos que parecen estar en contra de tal identificación: de un lado los hallazgos de monedas con leyenda laieśken se centran algo más al interior y se ha propuesto ubicar la ceca en el Llobregat medio (Villaronga, 1979, 130; id., 1982, 169); por nuestra parte no nos parece concluyente, pues por la misma razón habría que suponer a iltiŕta o ieśo en la costa, donde abundan más los hallazgos. Por otro lado, cuenta el problema que se plantea con la presencia de otra ceca a inicios del siglo I a. C. excesivamente cercana de Barcelona, la de baitolo. Sin embargo en este caso reparemos también en que, como hemos visto, debe corresponder a la fundación comprobada por la arqueología de Baetulo en el llano. A este respecto, se ha llamado la atención de la monumentalidad de la fundación augustea de Barcino en contraste con lo escaso de su núcleo urbano - aun tratándose de una colonia, poco más de $10 \mathrm{Ha}$ - lo que parece implicar una población dispersa e incluso el englobe en la misma de oppida cercanos, como Baitolo aún sin status (Guitart, 1993 b, 71). La otra ceca laietana, ilturo, aparece ya lejana, en el norte de territorio del populus. Es en cualquier caso de destacar el que laies'ken emita a lo largo de todo el siglo II a. C. y deje de hacerlo cuando lo hace precisamente baitolo. Cabe la posibilidad de que ésta última formara parte anteriormente de la ciuitas de laie, pues pensamos que efectivamente existió una con este nombre y que, como en el caso de auśa o iltiŕka el etnónimo haría referencia a los habitantes de una ciudad siguiendo las observaciones de Untermann (Untermann, 1992). Incluso si hiciera referencia al pueblo habría que suponer que las monedas se acuñaron en el lugar que ejercía la capitalidad del mismo. En definitiva parece que, como también otros autores habían propuesto (Martín Valls, 1967, 51), es lícito suponer nuestra ceca en Barcelona. Es cierto que no se han hallado tampoco monedas de ella en su casco urbano, pero también lo es que son pocas las publicadas, y entre éstas, evidentemente todas ellas residuales de los siglos II y I a. C., también brillan por su ausencia las de las otras cecas laietanas (Ripollés, 1982, 369-372).

lauro. Es posible que se trate de una localidad valenciana -incluso se ha propuesto en concreto Liria-, pero el hecho es que las monedas de esta ceca aparecen casi con exclusividad en Cataluña y, en ocasiones, como en los hallazgos de Balsareny y Cànoves - sobre todo-, en cantidad notable (Villaronga, 1979, 89; id., 1994, 195). Recientemente se ha documentado su presencia en tierras ausetanas junto a otras de cecas cercanas, catalano-costeras y alto-aragonesas (Molas et al., 1994, 46). En todo caso la tendencia más aceptada es situarla en Cataluña (Untermann, 1975, 198), y se ha propuesto, por su parecido toponímico con Llerona, en el Vallés, con lo que tendría sentido la distribución de los hallazgos (Estrada - Villaronga, 1967) y además, señalemos, el Vallés es una zona huérfana en cecas si aceptamos que laieśken no se ubicaba allí. Se trataría por tanto de una ceca layetana (Crusafont et al., 1986, 11). Recordemos que, en la etapa imperial, habrá en el Vallés un municipio, Egara (Tarrasa), del que no tenemos noticia de precedentes, pero nada hay que pueda ponerlo en relación con lauro, incluso parece estar en contra la diferencia toponímica. Guadán la sitúa en el grupo de auśesken (Guadán, 1969, 196), pero parece más evidente la influencia de kese (Villaronga, 1982, 174). También el parecido toponímico con Lloret de Mar (como asimismo la partida gerundense de Llorona) ha hecho que se indique como posible sede. Ciertamente es un argumento poco consistente, pero sí que es cierto que, no lejos, tenemos el problema de Blandae, uno de los oppida citados por Plinio que no tuvo ceca; desde luego ello no significa que se trate de la que nos estamos ocupando. En todo caso, recordemos una vez más que puede tratarse de una localidad valenciana. Acuñó bronces en el siglo II a. C. y la última emisión seguramente tuvo lugar poco antes de 104 a. C. (Villaronga, 1982, 174).

masonsa es un taller del grupo de kese que emite pocas monedas, quizás en la segunda mitad del siglo II a. C. (no es seguro), lo que ha llevado a suponerla ceca cesetana o al menos en la órbita de kese (Villaronga, 1982, 147; id., 1994, 173). La tendencia general es en cualquier caso considerarla ceca catalana (Untermann, 1975, 198), aunque en su día se llamó la atención sobre el hecho de que el 
único hallazgo conocido procedía de la aragonesa Alcañíz (Martín Valls, 1967, 54), lo que pudiera hacer dudar de que en efecto lo fuera.

olosoŕtin es la leyenda que presentan algunas imitaciones de dracmas ampuritanas emitidas durante la segunda guerra púnica que están presentes en el tesoro de Les Ansies, Gerona (Untermann, 1975, 179, Marchetti, 1978, 367). Pertenecen al grupo de aquéllas cuya asignación a una localidad conocida no es fácil. No obstante, en alguna ocasión se ha intentado relacionarla con los olositani, cuyo nombre parece haberse perpetuado en el actual Olot. Al mismo no se le conoce a través de las fuentes escritas, sino por medio de dos defixiones ampuritanas (Tovar, 1989, T-20). Sin embargo, no hay constancia de que fuera nunca ceca con posterioridad ni que hubiera una localidad romana en Olot. Quizás sea prudente no tomarla en consideración para nuestro fin dados los problemas, hoy insolubles, que plantea.

ore aparece como ceca, dentro del grupo ausetano, en la segunda mitad del s. II a. C. emitiendo una única y rara serie (Guadán, 1969, 198; Villaronga, 1982, 166). En general se conviene en la dificultad de ubicarla, aunque en un momento dado Villaronga la había creído en los Pirineos (Villaronga, 1961, 61), sin duda relacionándola con la actual Orrit próxima al Noguera ribagorzano. Que pudiera tratarse de ésta es posible si admitimos que a la misma alude la referencia a un Orritanus que en el s. II d. C. se trasladó a la cercana Aeso (Isona) (IRC II, 35). Es cierto que a favor de la identificación sólo podemos basarnos en el hecho del parecido toponímico y en que sus monedas estén en la órbita de influencia ausetana, lo que no sería de extrañar si también los estuvo la cercana aŕketurki, ubicada en La Seo de Urgel. Esta pretendida identificación fue asimismo sostenida por Martín Valls (1966, 255), pero en contra, Untermann la propuso en la costa (Untermann, 1964, 139). Sus monedas suelen aparecer entre la plana de Vic y el Vallés, pero su escaso número hace que pensemos que ello no es determinante como para situarla forzosamente en este espacio territorial (Pérez Almoguera, 1995). Si pensamos además en la posibilidad de poner el topónimo en relación con los airenosioi de Polibio (III, 35 , 1) o con los aresinari de Salustio (Hist. III, 5) - la tendencia ha sido situarlos en el valle de Arán-, parece que en efecto los Pirineos cuentan con más posibilidades que otros lugares para ser sede de la ceca. No obstante, no sabemos de la presencia de restos en Orrit adscribibles a esta etapa. Más difícil es que tengan que ver con ella las tempranas drac- mas de imitación ampuritana que aparecen con la leyenda oŕose (Untermann, 1975, 180; Villaronga, 1994, 42, núm. 41) que conocemos en el tesoro de Les Ansies (Gerona) (Marchetti, 1978, 367).

ośkum̄ken emite bronces en la segunda mitad del siglo II a. C. en número escaso. La tendencia general es suponerla ceca catalana, pero ello dista de resultar claro, pues al mismo tiempo se ha propuesto hacerlo en la región de Sagunto e incluso en la de Jaca (Untermann, 1975, 24). También se ha propuesto la posibilidad de que se trate de otra ilergete aunque ya en territorio oscense, por su parecido toponímico (Martín Valls, 1967, 58). Villaronga sin embargo la relaciona con lauro por la representación en sus monedas del torques rematado en cabeza de serpiente, y la supone entre las comarcas barcelonesas del Vallés y el Maresme (Villaronga, 1979, 211; id., 1994, 197), lo que nos remite al problema que plantea esta ceca, de la que ya hemos tratado.

otobesken suele identificarse con la Otogesa que menciona César en los acontecimientos del 49 a. C. entre Ilerda y el Ebro (b.c. 1, 61, 62), por lo que pudiera tratarse de una ceca catalana. Sin embargo ello no parece cierto: tradicionalmente se la relaciona con la Etebesa edetana (en realidad, sedetana) que cita Ptolomeo (II, 6, 62, 2), que no sería sino la Otobesa conocida por la epigrafía (CIL II 3794) (Untermann, 1975, 212) y quizás la etokisa que conocemos en imitaciones de dracmas ampuritanas (Villaronga, 1994, 51, núms. 96 a 100). Antes el propio Untermann la había incluido en el grupo regional de iltiŕta (Untermann, 1964, 145). Es, pues, muy probable que se trate de una localidad aragonesa que acuña en escaso número entre los años 133 y 82 a.C. (Guadán, 1980, 98). Villaronga por su parte la consideró en la Suessetania, entre el Ebro y la sierra de Alcubierre, pero en Aragón en todo caso (Villaronga, 1979, 193). Por tanto, parece oportuno prescindir de ella.

taŕakon es el topónimo que presentan unas dracmas de imitación emporitana de las que hemos tratado al referirnos a la ceca de kese.

untikesken es una importante ceca que comienza su actividad a inicios del siglo II a.C. y concluye en la primera mitad del siguiente (Villaronga, 1979, 125, 212, 223; id., 1994, 140). Se podría esperar, dada su importancia, que hubiera emitido denarios - sólo acuña bronces- en el momento que lo hacían kese e iltiŕta. Una explicación podría ser que 
siendo aliada de Roma se vería libre de un pago fijo como lo hacían las otras (García-Bellido, 1993, 113). Quizás no lo hizo por emitirlos Emporion, que continuó acuñando dracmas: si admitimos, como es lo más probable, que los étnicos en -sken aluden a los habitantes de una localidad (Untermann, 1992), ésta sería la discutida Indika que únicamente menciona Esteban de Bizancio (146 Watermann: Tovar, 1989, T-14, 37), que se supone vecina de la ciudad focense e incluso la propia Emporion (Padró - Sanmartí, 1992, 192; ya antes lo había propuesto Untermann, 1975, A-6, 165-172), como ciudad doble que era según Estrabón $(3,4,8)$. No se trata por tanto de una moneda genérica de los indiketes $\longrightarrow$ indigetes según Plinio (III, 21) — citados por Salustio (Hist. 2, 98, 5) y Estrabón (III, 4, 1), de los que debió ser capital por ser la que lleva un nombre derivado del populus; Ptolomeo sólo cita en su territorio dos localidades en la costa, Emporion y Rhode y otras dos en el interior, Deciana y Iuncaria (II, 6, $19 ; 6,71)$. Su papel trascendente se relaciona con la alianza de las ciudades griegas con los romanos (desembarco en Ampurias del 218), constituyendo la primera base de penetración peninsular, antes de ser sustituida por Tarraco. Es interesante señalar la posibilidad de que algunas series pudieran relacionarse con la fundación de la ciudad ortodoxamente romana en cuanto a su morfología - pero las monedas siguen ostentando caracteres ibéricos- que tuvo lugar a fines del siglo II o inicios del I a. C. según demuestra la arqueología (Aquilué et al., 1982): así las series 21 a 31 posteriores al 143 a. C. o de la 32 al final posteriores al 91 a. C. (Villaronga, 1982, 145) que pudieran corresponder a las necesidades de las guerras celtibéricas también, alguna o algunas de ellas, pudieran ser del momento de la fundación. La imprecisión en la cronología de las emisiones impide ser más taxativos.

Analizados los problemas que cada una de las cecas plantea, desde un punto de vista cronológico resulta el siguiente cuadro:

\begin{tabular}{|c|c|c|c|c|}
\hline ceca & $a$ & $\boldsymbol{b}$ & $c$ & $d$ \\
\hline abariltur (¿no catalana?) & - & - & Sí & - \\
\hline aŕketuŕki & - & SÍ & Sí & - \\
\hline auśa & - & SÍ & Sí & - \\
\hline baitolo & - & - & - & Sí \\
\hline baŕkeno & Sí & - & - & - \\
\hline eśo & - & - & - & SÍ \\
\hline euśtibaikula & - & Sí & SÍ & - \\
\hline ieśo & - & - & - & SÍ \\
\hline iltiŕka & SÍ & SÍ & SÍ & $?$ \\
\hline iltiŕta & Sí & Sí & Sí & SÍ \\
\hline ilturo & - & SÍ & Sí & $?$ \\
\hline kese & $?$ & SÍ & SÍ & SÍ \\
\hline laie & - & SÍ & SÍ & - \\
\hline lauro (¿no catalana?) & - & Sí & SÍ & - \\
\hline masonsa (¿no catalana?) & - & - & SÍ & - \\
\hline olośótin & Sí & - & - & - \\
\hline ore & - & - & SÍ & - \\
\hline ośkum̄ken (¿no catalana?) & - & - & SÍ & - \\
\hline taŕakon & Sí & - & - & - \\
\hline untika & - & SÍ & SÍ & SÍ \\
\hline
\end{tabular}

$\mathrm{a}=$ dracmas fines s. III a. C., $\mathrm{b}=1^{\mathrm{a}} \operatorname{mitad} \mathrm{s}$. II a. C., $\mathrm{c}=2^{\mathrm{a}} \operatorname{mitad} \mathrm{s}$. II a. C., $\mathrm{d}=1^{\mathrm{a}} \operatorname{mitad} \mathrm{s}$. I a. C., ? = quizás sólo inicios.

Hemos prescindido de baśti, bilauon, kaio y otobeśken, pues, además de ignorarse su ubicación, sus monedas son de cronología imprecisa. Aunque las hemos situado en el cuadro, por los problemas que presentan también de ubicación (algunas quizás ni siquiera catalanas), prescindiremos también de abariltur, lauro, masonsa, olośótin y ośkum̄ken. Se observa una continuidad especialmente destacable 
en el caso de iltiŕta y en el de kese, continuadora de taŕakon. También es de destacar el largo período de vigencia de untika, iltiŕka, ilturo y baŕkeno/laie si admitimos que se trata de la misma. Por último, destacan como nuevas fundaciones a inicios del I a. C. baitolo, eśo e ieso, las tres confirmadas por la arqueología. Las cuestiones que este panorama sugiere serán tratadas más detenidamente en los apartados que siguen.

\section{LOS PRECEDENTES DE LA SEGUNDA GUERRA PÚNICA}

Las dracmas de imitación ampuritana emitidas como consecuencia de la segunda guerra púnica lo son, como apuntábamos antes, con el fin ya sabido de satisfacer las demandas imperativas del conquistador. Se acuñan para financiar los gastos de los romanos, aunque al representar también una extensión en cuanto al número de cecas - antes sólo acuñaban las localidades griegas - significan también la inclusión de amplias zonas en la economía monetaria. Tales imitaciones nos ofrecen un primer indicio de las localidades que en ese momento jugaban un papel de importancia, aunque dado el número considerable de cecas no puede aceptarse que, frente a lo que ocurrirá con los denarios, la amonedación en plata signifique capitalidad regional. El problema radica en que no todas son de fácil identificación por cuanto una parte presentan como consecuencia de su propio carácter de imitación lecturas incomprensibles - en realidad son signos que nada indican-y, en otros casos, cuando la lectura es perfectamente ortodoxa se trata de nombres que no vuelven a aparecer con posterioridad ni en amonedaciones ni en las fuentes escritas o epigráficas, si bien es cierto que algunas de ellas resultan sugerentes como olosortin, tal como hemos visto en su apartado correspondiente. Otras como kertekunte o erur... quedan sin explicación satisfactoria, por no referirnos a las que presentan una transformación de los signos en un pseudoibérico a partir de la leyenda griega Emporiton (Villaronga, 1992 a). A pesar de la merma que ello representa, hemos de tomar sólo en consideración las que con toda seguridad nos mencionan cecas perfectamente identificables que, después de todo, serán además las únicas que tendrán continuidad en la emisiones del siglo siguiente. Son éstas taŕakon (o kese), baŕkeno (después laie), iltiŕta e iltiŕka. Significativamente corresponden a los antecedentes de las localidades que en Cataluña van a jugar el papel más destacado, y no sólo en la Antigüedad precisamente. Las tres pri- meras no ofrecen dificultad en cuanto a su identificación, aunque planteen problemas de los que hemos tratado antes (¿por qué taŕakon y baŕkeno no vuelven a acuñar con estos nombres y aparecen, aparentemente en su lugar, las cecas de kese y laie?). La última, iltiŕka, ya he indicado que en mi opinión hay que buscarla en el bajo Ebro, pudiendo considerarse la antecesora de Dertosa. No hay que incidir demasiado en el papel de capitalidad que siempre a lo largo de la historia, salvo momentos específicos, han jugado Tarragona, Barcelona, Lérida y Tortosa. A pesar de las dificultades expresadas seguirán jugando ese papel en la etapa siguiente, aunque si bien kese e iltiŕta emitirán de nuevo en plata, no ocurrirá otro tanto con las otras dos cecas, apareciendo sin embargo una nueva que cuenta con denarios, auso, sin antecedentes que sepamos en el siglo III a. C.

\section{LA ORGANIZACIÓN DE INICIOS DEL SIGLO II a. C. (figs. 1 y 2)}

Las campañas victoriosas del cónsul Catón en 195 significan, como se ha expresado en diversas ocasiones (Pena, 1992, 67), la verdadera incorporación de las tierras del nordeste peninsular a Roma. Es a partir de ese momento cuando comienzan a generalizarse las acunaciones de las diversas comunidades indígenas, salvo los posibles pero no seguros precedentes de kese que ya lo hace antes de 211 según Gimeno (1954) y de iltiŕta unos pocos años antes del cambio de siglo: he aquí una faceta del problema antes enunciado de falta de estratigrafías. A diferencia de la Ulterior en que todas se refieren inequívocamente a ciudades, aun cuando pudieran ser estructuras pseudourbanas (Chaves, 1994, 1306), en la Citerior, y en concreto en la zona que tratamos, tales acuñaciones aparecen desde el principio con leyendas en alfabeto indígena que se refieren a ciuitates -o a los habitantes de las mismas-, señal evidente de que éstas últimas existían o estaban en los preámbulos; así, se ha dicho en un trabajo ya clásico (y por cierto discutible en varios aspectos) que los romanos pudieron apoyarse en el tejido protourbano que había, al menos en algunas zonas, sin necesidad de modificaciones espectaculares (Jacob, $1985,19)$. Un buen exponente de ello puede ser el «poblado» de Burriac en Cabrera de Mar, seguramente la primitiva Ilturo antes de su traslado a Mataró, que conoce un gran auge a lo largo del siglo II llegando a las $10 \mathrm{Ha}$. de extensión (Guitart, 1993 b, 57). Que desde el punto de vista urbanístico no existiera una aglomeración importante como en Burriac 


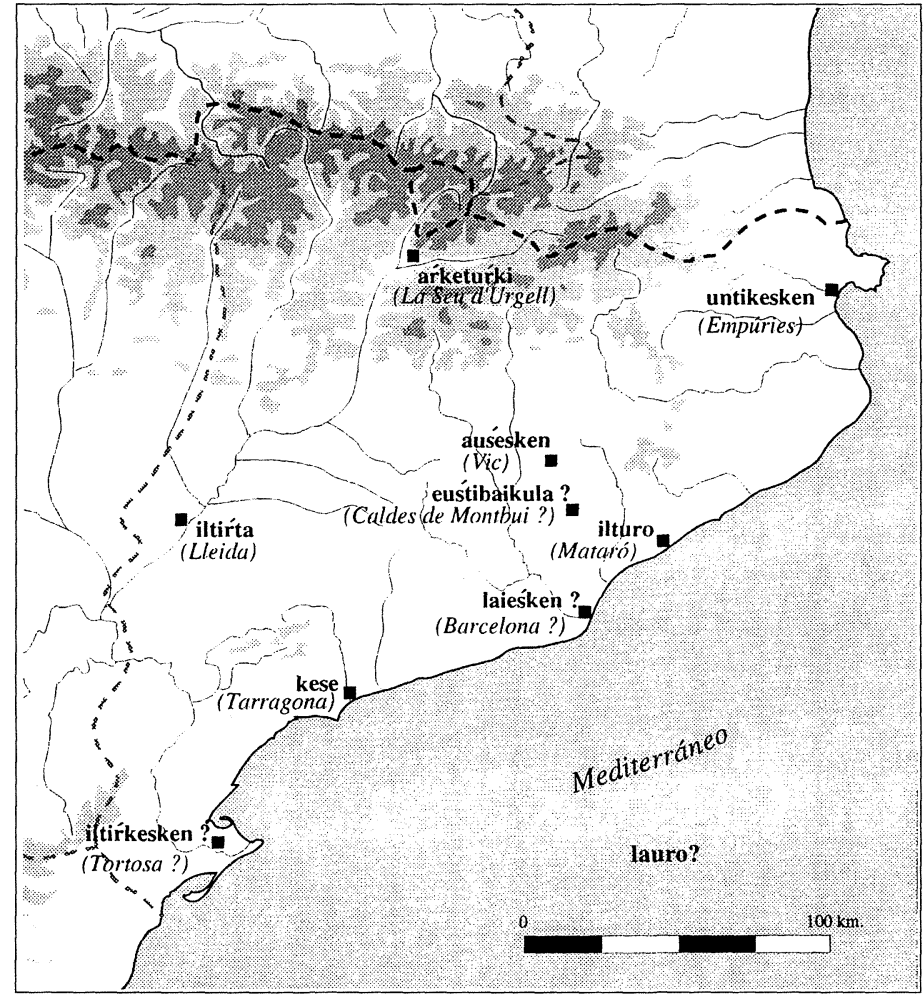

Figura 1.-Ubicación de las cecas de la primera mitad del siglo II $\quad$ a. C.

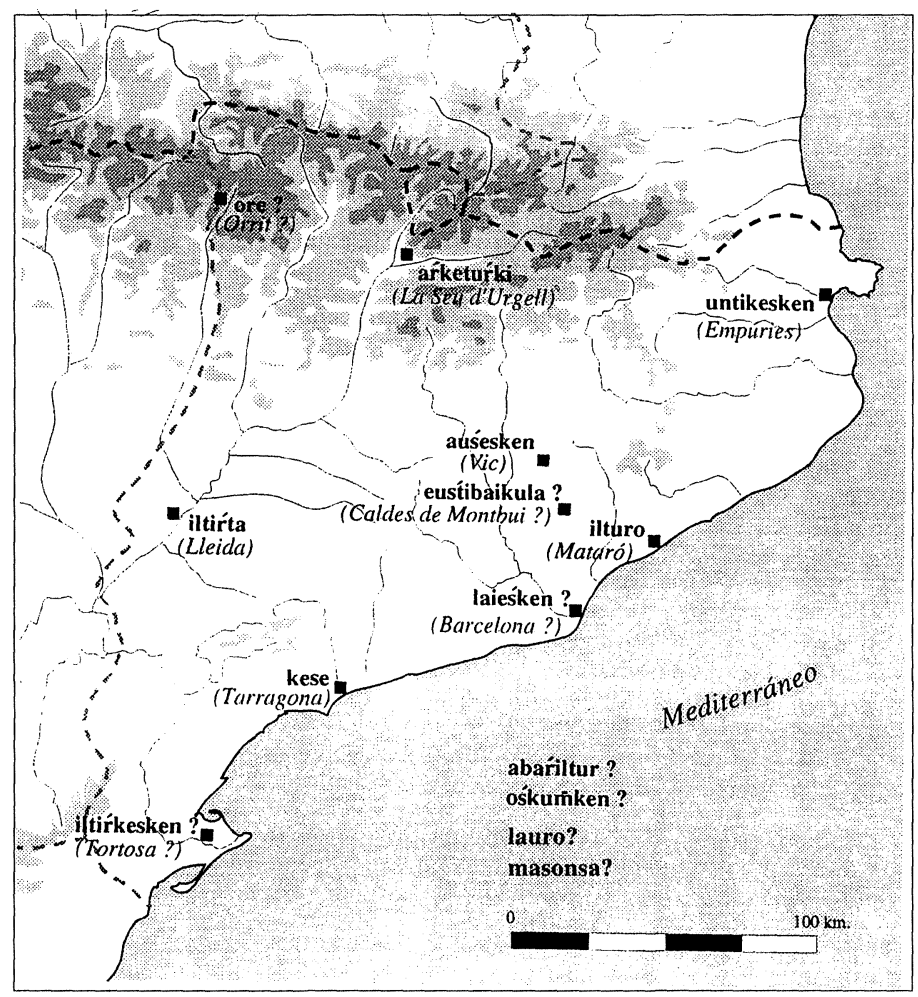

Figura 2.--Ubicación de las cecas de la segunda mitad del siglo il a. C. 
no es óbice para que nos refiramos a sociedades políadas: se trata de un elemento importante de las mismas, pero no imprescindible; una organización política de poblados puede serlo perfectamente. Estas ciuitates van a ser el eje sobre el que va a desarrollarse la primera organización territorial, consecuencia de la citada pacificación y consiguiente asunción de la conquista por Roma, que va íntimamente ligada a la admitida primera división provincial de esas fechas. Que no se trata de una organización estrictamente «a la romana»-extraña por lo demás en una época en que aún no se tiene experiencia en administrar tierras lejanas-, parece certificarlo el que para la misma se tomen como eje las principales localidades indígenas que ya debían serlo si, como es lógico suponer, las que emiten plata ejercen una capitalidad regional.

Destacan tres cecas que acuñan plata - las aludidas capitales regionales-: ausesken (de auso), kese e iltiŕta. Las tres son además cabeceras de grupos monetarios y emiten también en bronce. GarcíaBellido $(1993,109)$ cree que los denarios aparecen entre 180 y 178, relacionados con los cambios que la presencia de Graco comportó para la Citerior, no realizándose en todos los casos al unísono ni de una forma continuada, y no necesariamente con fines estrictamente militares, lo que de ser cierto representaría un cambio significativo con respecto a lo generalmente admitido. Como fuere, ilergetes y ausetanos son los pueblos más mencionados durante la etapa de conquistas por las fuentes escritas, los que ocupan una mayor extensión territorial, especialmente los primeros, y los que oponen una mayor resistencia a los romanos. Resulta pues perfectamente coherente que sus cabeceras ejercieran el papel de capitales en una primera organización (Pérez Almoguera, e.p. b). En cuanto a kese, si la identificamos con Tarraco, resulta también lógico que emita en plata por su condición de principal base romana primero y capital provincial después.

Las que sólo emiten bronces, junto con las anteriores, y a pesar de algunas dudas de identificación, nos permiten observar por su situación geográfica que no quedan grandes espacios sin cubrir, lo que equivale a decir que la presencia de ciudades o proyecto de tales auspiciadas por Roma afectaba a todo el espacio que tomamos en consideración. Además, el hecho de formar parte de una organización territorial perfectamente planificada por los conquistadores parece desprenderse del hecho de que todas las monedas presentan tipos uniformes, rasgo característico de la Citerior frente a la diversidad que presentan en la provincia meridional.

El occidente aparece presidido por iltiŕta, sin duda una de las cecas más importantes, al norte de la cual estuvo la ceca de aŕketuŕki, que creo situada en La Seo de Urgel. Este último hecho es importante en tanto que parece que se intentó englobar también a los Pirineos en la organización ciudadana, a diferencia de lo que sucederá en la organización de la siguiente etapa en que todas las localidades aparecen en el pre-Pirineo como muy al norte. También posiblemente en los Pirineos emitirá en la segunda mitad de siglo ore (¿Orrit?), lo que reforzaría esta idea. En el centro, y en torno a ausa, cabecera de los ausetanos, lo hará euśti o euśtibaikula, no localizada pero que bien pudiera corresponder a Caldas de Montbui, como hemos indicado. Ya en la costa, por el sur situamos la ceca de Ilerca, que hemos considerado el antecedente de Dertosa por diversos motivos, y quizás lo más razonable, dado el papel de los ilercavones y la importancia de la región donde se asentaron, hubiera sido esperar en ella moneda de plata (ya la tuvo durante la segunda guerra púnica). Más al norte, la importante ceca de kese (Tarragona) y, aún más norteña, laie, sobre la que ya hemos expresado nuestra opinión de que cuadraría más aparentemente con la continuadora de barkeno que con cualquier otra, y la también layetana ilturo, antecesora de Iluro (Mataró), que parece corresponder en ese momento al poblado de Burriac en Cabrera de Mar. Finalmente, la más septentrional, untika, con toda probabilidad la entidad indígena que convive con la griega Emporion. La continuidad, e incluso el aumento en una ceca en la segunda mitad del siglo, haya quizás que ponerlo en relación con la necesidad de erario para el ejército que está luchando en las guerras celtibéricas.

Lo importante, en definitiva, es que las cecas del siglo II a. C. nos están dibujando el panorama ciudadano resultante de una primera organización territorial que se basa, como decíamos, en la realidad indígena existente.

\section{LA ORGANIZACIÓN DE FINES DEL SIGLO II- INICIOS DEL I a. C. (fig. 3)}

En concreto se había comprobado que en torno a finales del s. II o principios del i a. C. se había llevado a cabo en nuestra zona la fundación - sobre realidades anteriores o no, aún no está satisfactoriamente aclarado- de ciudades ortodoxamente romanas desde el punto de vista urbanístico que conllevó la parcelación y organización de su ager correspondiente. Retengamos que coincide con el momento en que precisamente el desarrollo del sis- 


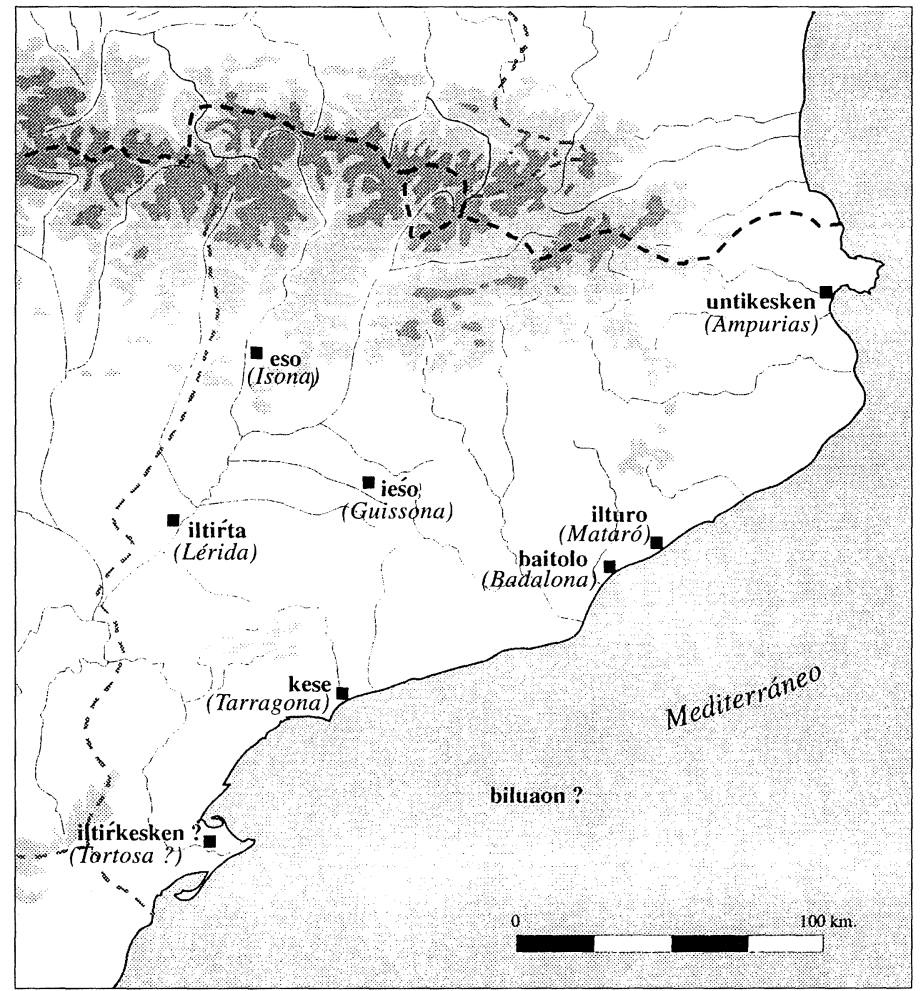

Figura 3.-Ubicación de las cecas de la primera mitad del siglo I a. C.

tema provincial romano tiene su momento decisivo (en torno al 100 a. C.), motivado tanto por la amenaza de Yugurta, como por las incursiones de cimbrios y teutones (Crawford, 1990, 105). A ello, añadiríamos nosotros, tampoco sería ajena la actividad de los aún no pacificados celtíberos en esos momentos. Es posible que el antecedente más lejano de esta nueva organización haya que buscarlo en la que tras la caída de Numancia se propusieron realizar los romanos, según indican las fuentes escritas.

Era la primera vez que en nuestra zona se producía una organización «a la romana», pues, como hemos visto, tras la pacificación de Catón el Censor se había reorganizado el territorio, pero en base a las realidades indígenas sin que el campo se viera afectado por la acción de los agrimensores, al menos de una manera global. Que las nuevas fundaciones tal como expresábamos en la introducción carecieran paradójicamente de status romano o latino parece cierto, como lo demuestra la ausencia de noticias de $\tan$ trascendente hecho en las fuentes escritas. Además, en los casos que sabemos de la coincidencia de fundaciones y cecas, todas las monedas siguen con caracteres y nombres indígenas. Lo que sucede en Cataluña se englobaría en un proyecto que abarca desde la Liguria, pasando por la
Provenza - donde se funda la colonia de Narbo hacia 118 a. C.-, y que llega hasta la Celtiberia aún no del todo pacificada como decíamos (Pérez Almoguera, 1994): no es casual que precisamente a partir del último tercio del siglo II sea cuando comienzan a acuñar muchos nuevos talleres, sobre todo en la cuenca del Ebro (Ripollés, 1982, 518), más cercanos a la zona conflictiva y que también servirían para financiar los gastos bélicos.

Las nuevas fundaciones estaban generalmente enclavadas en la línea de la costa y en lugares estratégicos del interior, cumpliendo la función militar de vigilancia de las rutas (Guitart, 1993 a). En parte serán continuadoras de anteriores núcleos desplazados o no de su solar previo-y en otros $e x$ nouo. El conocimiento de tan trascendental hecho hemos de reconstruirlo a través de la arqueología, lo que significa que el fenómeno que conocemos desde hace pocos años se ha comprobado en algunos yacimientos favorecidos por la excavación programada y es posible que haya más fundaciones aún no comprobadas. Incluso antes de que se planteara el problema como fenómeno que afectaba a una amplia zona ya se había llamado la atención de la construcción de las murallas de Emporiae y de Baetulo por esas fechas, considerándose consecuencia 
del peligro generado por «la invasión cimbria» de 104 a.C. (Guitart, 1976, 239; Villaronga, 1983, 106). Resulta altamente significativo que casi todas las localidades que sabemos por la arqueología que se fundan entonces sean cecas. Así, aunque el numerario emporitano (en nuestro caso, untika) es continuo, es entonces cuando tiene lugar la construcción del primer foro romano, con todo lo que ello representa (Aquilué et al., 1982). En cuanto a Tarraco (o si preferimos kese/Tarraco), base principal y capital provincial, el estudio de su ager indica también la aparición de las primeras uillae por estos momentos (Keay et al., 1990, 126). ilturo (Mataró) es continuadora de la ceca que debía encontrarse en Burriac, Cabrera de Mar. También se fundan entonces baitolo (Badalona), eso (Isona), o ieśo (Guissona). Con respecto a estas dos últimas, es de señalar que se encuentran en el pre-Pirineo en tierras con más posibilidades, desapareciendo las situadas en pleno Pirineo que antes sí había sido englobado en la organización ciudadana (aŕketuŕki, ore). iltiŕta, que sigue emitiendo, es posible que conociera ahora su primera fundación a la romana en la zona vecina a la colina de la Seo donde se habría desarrollado - y seguiría desarrollándose- la población anterior, según podría desprenderse de intervenciones arqueológicas aún no publicadas. Los ilerdenses, ya con ciudadanía romana, que figuran en el Bronce de Ascoli de 90 a. C. serían el exponente de unos aristócratas admitidos en el grupo dirigente.

Sin embargo, no quiere ello decir que nueva fundación equivalía automáticamente a ceca. Sin perjuicio de aquellas cuya ubicación desconocemos, como las pobres en emisiones - tanto que sólo se cuenta con algún raro ejemplar-basti y biluaon, y de que algunas de las que se consideran de la segunda mitad del siglo II, por la falta tantas veces argüida de estratigrafías, pudieran ser algo más tardías y tener aquí cabida, sabemos que localidades que se fundan también por entonces no emiten moneda. Sería el caso de la costera Blandae (Blanes) y de la cercana a la misma Gerunda (Sanmartí, 1993, 210). Gerun$d a$ sin embargo es posible que se fundara algo más tarde, aunque desde luego en el primer tercio del siglo i a.C. (Nolla, 1987, 13, 27), lo que hace pensar que quizás no formara parte de la ordenación y se hubiera fundado como control de la vía necesaria para el traslado de los ejércitos optimates en su lucha contra Sertorio, pero ello no es sino una hipótesis y quizás sea más razonable pensar que debía formar parte del mismo plan de ordenación territorial del que tratamos, no necesariamente realizado al unísono sensu stricto. Precisamente, el caso de
Gerunda en cuanto a cronología puede coincidir con el de Iluro-Mataró, donde los materiales fundacionales - se dice - no son anteriores a 75 a. C., y también con el de Baetulo donde las estratigrafías más antiguas hasta el momento son del segundo cuarto del siglo I a.C. (Aquilué - Subías, 1986, 353) —aunque son pocas y hay materiales más antiguos fuera de contexto-, lo que ha dado pie para que se piense en posibles fundaciones pompeyanas (Olesti, 1993, 245). Ello conllevaría pues que no todas las fundaciones tuvieran lugar a la vez, mediando un período de medio siglo entre el inicio o el final del proceso, o bien que hay que afinar más la cronología aún imprecisa en muchos yacimientos. Significaría además que lo que se había iniciado como posible pantalla entre Italia e Hispania a través de la Narbonense hasta la Celtiberia para evitar posibles nuevas invasiones del calibre de la de los cimbrios y tener una retaguardia segura tras los aún díscolos celtíberos, fue concluido por Pompeyo como consecuencia de una guerra civil, la de los optimates contra el popular Sertorio. No obstante subsiste el hecho de que en la Layetania y en concreto en torno a Baetulo y a Iluro, el modelo agrícola basado en las uillae - aunque no desaparezcan radicalmente los antiguos asentamientos-, que razonablemente hay que poner en relación con una ordenación global, aparecen, como en la zona de Tarraco, a fines del siglo II a. C. (Prevosti, 1981; id., 1982; Ruiz - Molinos, 1993, 277), lo que hace que siga siendo válida la propuesta de nueva reorganización para esas fechas.

Como apuntábamos, parece que buena parte de las fundaciones con precedentes no ocuparon en lo que a su centro urbano se refiere el mismo lugar que lo había hecho el anterior, lo cual resulta natural pues éstos en buena parte serían de poca entidad o motivos de otra índole aconsejarían su traslado, pero nunca lejos del lugar donde se supone estuvo el anterior, en su territorium en suma. Creo que no es necesario pensar que fuese una norma general, como parece inferirse de algunos trabajos (Pina, 1993) aparecidos a partir de la propuesta de F. Burillo, que consideró, hace más de una década, un diferente solar para la Bilbilis celtibérica del de la Bilbilis Italica (lo mismo ocurriría en Segeda) y su suposición de que ello ocurriría en más casos (Burillo - Ostalé, 1983-84). Evidentemente la nueva fundación emporitana estuvo junto a la neapolis griega, y parece que lo mismo podría decirse de Tarraco con respecto al precedente poblado indígena. En cuanto a Ilerda parece lógico que estuviera en la mejor elevación de la comarca, la colina de la Seo en cuyas faldas se desarrolló la ciudad romana, como hemos visto en su apartado. Aeso se asentó 
sobre población anterior, según se desprende de las últimas intervenciones... El caso más claro de la zona que nos ocupa, en lo que respecta a su cambio de ubicación de centro urbano principal, es en algunas ciudades marítimas como Baetulo o Iluro, antes situadas más tierra adentro, como por otra parte es normal entre los iberos, que se trasladan a la costa, a lo que no debió de ser ajeno un mejor control de la uia Heraclea.

\section{LA MUNICIPALIZACIÓN AUGUSTEA}

Nos resta finalmente observar los cambios producidos en el tejido urbano que acarreará la municipalización, que tendrá su momento álgido en época de Augusto y que se completará bajo los flavios.
Es una cuestión que, dados los propósitos de nuestro trabajo, no vamos a abordar si no es con la única intención de observar perduraciones o desapariciones con respecto a lo que para las etapas anteriores nos informaba la numismática. Se trata, como es bien sabido, de una etapa en que las cecas, evidentemente ya con caracteres y nombres latinos como corresponde a unas colonias y municipios ortodoxamente romanos, se ven drásticamente reducidas ya en los inicios de la adquisición de status: sólo acuñarán bajo Augusto Emporiae (quizás incluso algo antes), Ilercauonia (que después lo hará con el nombre de Dertosa), Tarraco e Ilerda. La última desaparecerá con el primer emperador y las demás no pasarán de Tiberio (Dertosa) y Calígula (Emporiae, Tarraco). El siguiente cuadro nos ilustra sobre los cambios.

\begin{tabular}{|l|c|c|}
\hline col./municip. & precedentes & Augusto o post. \\
\hline Aeso & Sí & - \\
\hline Aquae Calidae & - & - \\
\hline Ausa & SÍ & - \\
\hline Baetulo & Sí & - \\
\hline Barcino & Sí & - \\
\hline Blanda & - & - \\
\hline Caldas Montbui & - & - \\
\hline Dertosa & Sí & SÍ \\
\hline Egara & - & - \\
\hline Emporiae & Sí & SÍ \\
\hline Gerunda & - & - \\
\hline Iesso & Sí & - \\
\hline Ilerda & SÍ & SÍ \\
\hline Iluro & Sí & - \\
\hline Iulia Liuica & - & - \\
\hline Rhodae & - & - \\
\hline Sigarra & - & - \\
\hline Tarraco & Sí & Sí \\
\hline
\end{tabular}

Hemos exceptuado en esta lista, como también lo hemos hecho en los apartados anteriores, las emisiones griegas de Emporion y Rhode por tratarse de un problema evidentemente distinto de las ibéricas. Observando el comportamiento de las diversas cecas, resalta la continuidad de la capital provincial, sin duda la más importante de todas, y la certificación de que Ilerda aún juega un importante papel como principal localidad del interior, papel que irá perdiendo a partir de Augusto en beneficio de Cae- saraugusta. Desde luego también Emporiae, como era de esperar, es una ceca activa, como asimismo Dertosa, la posible sucesora de iltirka, tal como corresponde a la ciudad que preside el curso bajo del Ebro. Otros municipios que no tienen antecedente conocido nos plantean un importante problema: ¿corresponden a las cecas republicanas de las que ignoramos su ubicación?; quizás en algún caso no es imposible, aunque no podemos ir más allá de la suposición. 


\section{CONCLUSIÓN}

Así, pues, examinados los problemas que cada ceca plantea por los motivos expresados en su apartado correspondiente, parece razonable que podamos prescindir de basti, biluaon, kaio, lauro, masonsa, ośkun̂ken y otobesken. También, y aún admitiendo que fue ceca catalana, hemos de prescindir de la olosortin de las dracmas de imitación emporitana y situarla junto a las otras de difícil adscripción y que incluso, a veces, no presentan sino imitaciones de signos que no corresponden ni a ciudades ni a pueblos concretos. A partir de inicios del s. II a.C., cuando aparecen buen número de cecas que acuñan con módulos romanos, es cuando se procede a una primera organización a partir de las realidades indígenas. Las monedas en este momento nos ofrecen, creo, junto con los precedentes de las imitaciones de dracmas de la segunda guerra púnica, el panorama de entidades ciudadanas correspondientes a diversos populi con que contaba el país. Los conquistadores estimularían esta realidad en su beneficio de cara al pago de sus tropas. El interés de tales emisiones se acrecienta al darnos información de tan importante aspecto al que las fuentes escritas, por sus características y su intencionalidad, apenas dedican atención ofreciendo escasos datos y siempre con carácter subsidiario. Las que emiten denarios en un momento dado significan capitalidad regional, pero son bastantes más las que lo hacen en bronce ayudándonos a completar el mapa de distribución ciudadana. Aun prescindiendo de las cecas no ubicadas con seguridad, éste resulta muy coherente: ninguna zona queda vacía de cecas, incluidos los Pirineos, lo que quiere decir que en la organización se engloba todo el territorio catalán, incluyendo las tierras aparentemente más marginales.

En lo que respecta a la organización, ya a la romana, de fines del siglo II e inicios del i a. C., los cambios son significativos y prefiguran la organización municipal que tendrá lugar a finales de siglo. Las fundaciones comprobadas por la arqueología sobre realidades anteriores o ex nouo emiten en su mayoría monedas, algunas durante un breve período de tiempo (básicamente las nuevas). Las cecas anteriores más importantes siguen, con alguna notable excepción para la que no es fácil encontrar explicación clara (casos de ausa o iltirka), si no es la tendencia a la reducción de talleres que aparece bien reflejada cuando se produce la municipalización augustea y las leyendas de los reversos tienen ya caracteres latinos. Los Pirineos aparecerán huérfanos de entidades ciudadanas en esta etapa, lo que explica la posterior ausencia de municipios en los mismos.

A guisa de colofón, quisiera indicar que soy muy consciente de la provisionalidad de muchas de las posibilidades que se apuntan, como la referida, ciertamente hipotética, a alguna de las propuestas de ubicación de cecas, que necesitan de una comprobación que ojalá el futuro pueda precisar en su certeza o no. De hecho he apuntado una serie de sugerencias basadas en una lógica que sólo puede ser aparente, pero que he procurado que se apoyara en los datos históricos conocidos de tiempo y en los arqueológicos con que hoy contamos tras una década especialmente pródiga en novedades.

\section{BIBLIOGRAFÍA}

Adserias, M., Burés, L., Miró, M. T., y Ramón, E., 1993: «L'assentament pre-romà de Tarragona», Revista d'Arqueologia de Ponent, 3, 177 227

Alföldy, G., 1991: Tarraco, Forum 8, Tarragona.

Aquilué, X., y Subías, E., 1986: «Sobre la fundació de la ciutat romana de Baetulo (Badalona)», $6 e$. Col.loqui Int. d'Arqueologia de Puigcerdà (1984), Puigcerdà, 353-359.

Aranegui, C., 1994: «Arse-Saguntum: una estrategia para consolidar el poder», Leyenda y arqueología de las ciudades prerromanas de la Península Ibérica I, Madrid, 31-43.

BARBERÀ, J., y DUPRÉ, X., 1984: «Els laietans, assaig de síntesi», Fonaments, 4, 31-86.

Beltrán, P., 1953: «Las cecas pirenaicas», Pirineos, 27, 17-51.

BlaNCH, R. M., et al., 1994: «Un gran magatzem laietà al Mont Jovis: les sitges del port (Montjuïc, Barcelona)», III Congrés d'historia de Barcelona (1993), Barcelona, 119-127.

Burillo, F., y Ostalé, M., 1983-84: «Sobre la situación de las ciudades celtibéricas Bilbilis y Segeda», Kalathos, 3-4, 287-309.

CAmpo, M., 1974: «La ceca de Abarildur y un nuevo tipo de moneda anepígrafa», Miscelánea Arqueológica. XXV Aniversario de los cursos de Ampurias I, Barcelona, 223-228.

Campo, M., y Granados, O., 1978: «Aproximación a la circulación monetaria de Barcino», Numis$m a, 150-155,221-240$.

Campo, M., y Granados, O., 1979: «Aproximación a la circulación monetaria en la Colonia Barcino», Symposium Numismático de Barcelona, I, Barcelona, 57-69.

Castellà, J., et al., 1986: Campanyes d'excava- 
cions arqueològiques a Els Prats de Rei (19721975), Els Prats de Rei.

CERDÀ, J. A., et al., 1993: «Iluro, oppidum ciuium Romanorum: estat de la qüestió», La ciudad en el mundo romano. XIV Congreso Int. Arq. Clásica, Pre-actas, II, Tarragona, 87.

Chaves, F., 1994: «Moneda y ciudad en el Sur de la Península Ibérica», L’Africa romana (dic. 1992), Sassari, 1305-1318.

Clariana, J. F., 1994: Iluro ciutat romana, Mataró.

Collantes, E., 1987-1989: «Conjeturas sobre metrología ibérica», Numisma, 204-221, 29-107.

Crawford, M. H., 1990: «Origini e sviluppi del sistema provinciale romano», en SCIAvONE, A. (dir.), Storia di Roma. 2. L'impero mediterraneo, Torino, 99-121.

Crusafont, M., García, M., y Balaguer, A. M., 1986: Història de la moneda catalana, Barcelona.

Estrada, J., y Villaronga, L., 1967: «La Lauro monetal y el hallazgo de Cánoves (Barcelona)», Ampurias, XXIX, 135-194.

FAtÁs, G., 1992: «Para una etnogeografía de la cuenca media del Ebro», Paleoetnología de la Península Ibérica, Complutum, 2-3, 223-232.

FLeTCHER, D., 1989: «Breves comentarios sobre las dracmas ibéricas con salir», Arse, 24, 821-824.

GABBA, E., 1973: Essercito e società nella tarda repubblica romana, Firenze.

García-Bellido, M. P., 1990: El tesoro de Mogente y su entorno monetal, Valencia.

García-Bellido, M. P., 1993: «Origen y función del denario ibérico», Sprachen und Schriften des antiken Mittelmeerraums. Festschrift für Jürgen Untermann, Innsbruck, 97-121.

Genera, M., 1993: «Dertosa: una ciutat romana», La ciudad en el mundo romano. XIV Congreso Int. Arq. Clásica, Pre-actas II, Tarragona, 140.

Gimeno, F., 1954: «Los problemas planteados por las cabezas barbadas de Cose», Numisma, IV, núm. 12, jul.-sept., 21-33.

Guadán, A. M. de, 1969: Numismática ibérica e ibero-romana, Madrid.

Guadán, A. M. de, 1980: La moneda Ibérica. Catálogo de Numismática ibérica e ibero-romana, Madrid.

Guadán, A. M. de, y Villaronga, L., 1968: «Las corrientes económicas del nordeste hispánico a la luz de las fuentes numismáticas», Papeles del Laboratorio de Arqueología de Valencia, 5, Valencia, 55-61.

Guitart, J., 1976: Baetulo. Topografía arqueológica, urbanismo e historia, Badalona.

Guitart, J., 1993 a: «Un programa de fundacions ur- banes a la Hispania Citerior de principis de segle I a. C.», La ciudad en el mundo romano, XIV Congreso Int. Arq. Clásica, Pre-actas I, Tarragona, 93-99.

Guitart, J., 1993 b: «La ciudad romana en el ámbito de Catalunya», La ciudad hispanorromana, Barcelona, 54-83.

Guitart, J., y Pera, J., 1993: «La ciutat romana de Iesso (Guissona, La Segarra)», La ciudad en el mundo romano. XIV Congreso Int. Arq. Clásica, Pre-Actas II, Tarragona, 161.

ICART, J., 1993: «Cal.lipolis fou Tàrraco», Faventia, 15-1, 79-89.

JАCOB, P., 1985: «Le role de la ville dans la formation des peuples ibères», Mélanges de la Casa de Velázquez, XXI, 19-56.

JUNYENT, E., 1994: «Iltirda», Leyenda y Arqueología de las ciudades prerromanas de la Península Ibérica, II, Madrid, 77-94.

Keay, S. J., Carreté, J. M., y Millet, M., 1990 : «Ciutat i camp en el món romà: les prospeccions a l'Ager Tarraconensis», Tribuna d'Arqueologia 1988-1989, Barcelona, 121-129.

MARChetTI, P., 1978: Histoire économique et monétaire de la deuxième guerre punique, Bruxelles.

MARTín VALLS, R., 1967: «La circulación monetaria ibérica», BSEAA, XXXII, 207-366.

Mateu Llopis, F., 1947: «Identificación de cecas pirenaicas. Ensayo de localización de topónimos monetarios altoaragoneses», Pirineos, 5, 39-80.

Miró, C., Monleón, A. M., y Revilla, E., 1993: «El nucli romà de Caldes de Montbui. Estat de la qüestió», La ciudad en el mundo romano. XIV Congreso Int. Arq. Clásica, Pre-actas II, Tarragona, 225.

Miró, J., Pujol, J., y García, J., 1988: «El dipósit del sector occidental del poblat ibèric de Burriac (Cabrera de Mar, El Maresme)», Laietania, 4.

Molas, M. D., 1982: Els ausetans $i$ la ciutat d'Ausa, Vic.

Molas, M. D., et al., 1994: «El Camp de les Lloses, un establiment ausetà de la segona meitat del segle II a.C.», Llibre de Tona, Tona, 43-50.

Nolla, J. M., 1987: Girona romana. De la fundació a la fi del món antic, Girona.

Nolla, J. M., 1993: «Les ciutats del nord-est de Catalunya. Els municipis flavis», Homenatge a Miquel Tarradell, Bárcelona, 659-665.

Olesti, O., 1993: «Les actuacions pompeianes a Catalunya: reorganització del territori i fundació de noves ciutats», La ciudad en el mundo romano. XIV Congreso Int. Arq. Clásica, Pre-actas II, Tarragona, 245.

PAdRó, J., y SANMARTí, E., 1992: «Areas geográficas 
de las etnias prerromanas en Catalunya», $P a$ leoetnologia de la Península Ibérica, Complutum, 2-3, 185-194.

PANOSA, M. I., 1993: «Algunes qüestions sobre l'epigrafia de les llegendes monetals ibèriques», Studia Palaeohispanica et indogermanica J. Vntermann ab amicis oblata, Barcelona, 199-212.

PayÀ, X., Puig, F., y Reyes, T., 1994: «Primeres datacions dels nivells fundacionals d'Aeso», Revista d'Arqueologia de Ponent, 4, 151-172.

PenA, M. J., 1984: «Apuntes y observaciones sobre las primeras fundaciones romanas en Hispania», Estudios de la Antigüedad, 1, 49-85.

PenA, M. J., 1988: «Hipòtesis noves sobre Empúries a partir de l'anàlisi de les fonts literaries», Fonaments, 7, 12-45.

PenA, M. J., 1989: «Avieno y las costas de Cataluña y Levante I. Tyrichae: TYRIKAI, ¿la Tiria?», Faventia, 11/2, 9-21.

Pena, M. J., 1992: «Emporiae», Dialoghi di Archeologia, 10, 1-2, 65-77.

Pena, M. J., 1993: «Algunas precisiones sobre el estatuto jurídico de Dertosa», II Congreso Peninsular de Historia Antigua, Coimbra, 581-596.

Pérez Almoguera, A., 1993: «Sobre las fundaciones republicanas en Hispania. El caso de Ilerda», $L a$ ciudad en el mundo romano. XIV Congreso Int. Arq. Clásica, Pre-actas II, Tarragona, 256.

Pérez Almoguera, A., 1994: «En torno a la ordenación del territorio y fundaciones romanas en el interior de Cataluña a fines del siglo II e inicios del I a.C.», III Congreso Peninsular de Historia Antigua, Preactas II, Vitoria, 446-455.

Pérez Almoguera, A., 1995: «Dos posibles cecas del Pirineo Oriental y la ordenación territorial romano-republicana», I Encuentro Peninsular de Numismática Antigua. La moneda Hispánica: Ciudad y Territorio, Anejos de AEspA, XIV, Madrid, 225-230.

Pérez Almoguera, A., en prensa a: «De la Arketurki prerromana a la Vrgellum visigoda, ¿una continuidad?», Cypsela, XI, 1995.

Pérez Almoguera, A., en prensa b: «Iltirta yAuso, dos capitales regionales en la Hispania republicana», Anales de Prehistoria y Arqueología, 9, 1995.

Pérez, A., y Soler, M., 1993: «Les seques d'Iltirta i Iltiraka i el llop ibèric», RAP, 3, 151-175.

PINA, F., 1993: «¿Existió una política romana de urbanización en el nordeste de la Península Ibérica?», Habis, 24, 77-94.
Prevosti, M., 1981: Cronologia $i$ poblament a l'àrea rural de Baetulo, Badalona.

Prevosti, M., 1982: Cronologia $i$ poblament a l'àrea d'Iluro, 2 vols., Mataró.

RodÀ, I., 1992: «El monument de Malla», Roma a Catalunya, Barcelona, 18-21.

Ripollés, P. P., 1982: La circulación monetaria en la Tarraconense mediterránea, Valencia.

Ruiz, A., y Molinos, M. 1993: Los Iberos. Análisis arqueológico de un proceso histórico, Barcelona.

SANMARTí, E. 1993: «Urbanización y configuración territorial del noreste de la Citerior durante la época romano-republicana», La ciudad en el mundo romano. XIV Congreso Int. Arq. Clásica, Pre-actas I, Tarragona, 205-212.

SiLEs, J., 1985: Léxico de inscripciones ibéricas, Madrid.

Tovar, A., 1989: Iberische Landeskunde, 3. Tarraconensis, Baden-Baden.

Untermann, J., 1964: «Zur Gruppierung des Hispanischen Reitermünzen», $M M$, 5, 91-155.

Untermann, J., 1975: Monumenta Linguarum Hispanicarum I, Wiesbaden.

UnTERMANN, J., 1992: «Los etnónimos de la Hispania antigua y las lenguas prerromanas de la Península Ibérica», Paleoetnología de la Península Ibérica, Complutum, 2-3, 19-33.

VILlARONGA, L., 1961: «El hallazgo de Balsareny,» Numario Hispánico, X, 9-102.

VillaronGA, L., 1966: «Los inicios de la acuñación del denario ibérico», IX CNA (Valladolid, 1965), Zaragoza, 301-307.

Villaronga, L., 1978: Las monedas ibéricas de Ilerda, Barcelona.

VILLARONGA, L., 1979: «La circulación monetaria en Azaila (Teruel)», Symposium Numismático de Barcelona, II, 35-37.

VillarongA, L., 1982: «Les seques ibèriques catalanes: una sintesi», Fonaments, 3, 135-183.

VILlaronga, L., 1983: Les monedes ibèriques de Tarraco, Tarragona.

VillarongA, L., 1988: «Les dracmes ibèriques de Tàrraco», Faventia, 10, 1/2, 143-152.

VILLARONGA, L., 1992 a: «Les dracmes ibèriques d'imitació emporitana amb l'arrel BELSE o OLSE», Numisma, 230, 17-25.

Villaronga, L., 1992 b: «Les primeres monedes de Tarraco», Butlletí Arqueològic, V, 14, 89-105.

Villaronga, L., 1994: Corpus Nummum Hispaniae ante Augusti Aetatem, Madrid. 